\title{
Entrepreneur Philanthropy: What is the Appropriate Donation for a Named Gift?
}

\author{
Derek Dictson (New Mexico State University Foundation) \\ James Hoffman (New Mexico State University) \\ James $C$ Wetherbe (Texas Tech University)
}

KEYWORDS: Higher Education, Philanthropy.

Companies led by entrepreneurs allocate more than twice the percentage of profits to charity than many of America's largest companies, a fact noted in an earlier EIX article, "Perils of Entrepreneurial Philanthropy in Higher Education." (https://eiexchange.com/content/263-perils-of-

entrepreneurial-philanthropy-in-higher) From the Gates Foundation and its focus on human health, to the $\$ 100$ million that Facebook's Mark Zuckerberg donated to Newark's public schools, many wildly successful entrepreneurs generously give back to the world.

In fact, EIX.org(https://eix.org) (https://eix.org) is possible because of entrepreneur Richard Schulze, founder of Best Buy. Through The Richard M. Schulze Family Foundation, Schulze aspires to help more entrepreneurs succeed through providing EIX.org(https://eix.org) (https://eix.org) as a free learning resource to professors, students and practitioners of entrepreneurship. Successful entrepreneurs, he reasons, create more jobs and improve the economy and society. To help future entrepreneurs, Schulze also endowed the Schulze School of Entrepreneurship at the University of St Thomas in the Twin Cities of Minnesota.

The primary motivation for this entrepreneurial philanthropy? It is a belief in giving back as an individual, and a desire to encourage that philosophy within the corporate culture, according to a 2010 study conducted by Fidelity Investments $\AA$ Charitable Gift Fund. But the Fidelity study also revealed that more than half of entrepreneurs rely on their own judgment or the advice of those closest to them about donations, including best practices.

This practice can lead to unanticipated and undesired outcomes, such as a donor feeling a gift was undervalued relative to comparable gifts made by other donors. This is especially likely to happen at universities, where gifts are often tied to naming opportunities. One reason for this is that those receiving gifts are often more experienced and skilled at receiving than donors are at giving, thus creating a knowledge gap that can lead to misunderstandings.

Common types of gifts usually named to honor the donor or some person(s) selected by the donor include buildings and facilities, named colleges and programs, scholarships, and professorships.

Naming gifts is a productive idea in that it not only recognizes the donor but perhaps more importantly provides awareness that important people care about and are supporting an institution. This encourages others in a similar position to do the same. But what is an appropriate or fair gift to have a building or program named after a donor? This article explores several ways this valuation is conducted by fund raisers, so that entrepreneurial donors won't be at an informational disadvantage. With an understanding of the methods, philanthropic entrepreneurs are in a knowledgeable position to negotiate the valuation method.

\section{Endowment vs Current Use Donations}

Before exploring methods, it is worth noting that a named gift can be an endowment with the intent of creating an income stream to support or cover ongoing cost. Alternatively, the gift can be a "current use" gift to cover a cost for a specified period of time, after which a renewal or a new renaming opportunity occurs. Also, a donation - whether endowment or current use - may cover all or a portion of the cost.

With that in mind, here are common valuation methods, which include asset, market, build-up, income, and 
discounting methods.

\section{Asset Method}

This is based on the cost of space for a program and/or yearly cost to operate the program. Use a "bottom up" approach that is driven by how much new annual revenue the program needs to generate. To determine the endowment needed for long term funding, the college/program would typically look at budgets and future plans to determine the level of additional annual funding necessary to achieve an elevated and sustained level of excellence.

To calculate the necessary endowment, the annual funding can be multiplied by 25 , assuming for the sake of argument a $4 \%$ yearly return on the endowment. For example, if the necessary endowment is $\$ 100,000$, then the endowment needs to be $\$ 2.5$ million (i.e., based on a $4 \%$ yearly return on the endowment). If the number is $\$ 25,000$ per year then the endowment needs to be $\$ 635,000 \quad(\$ 635,000 \times 4 \%$ yearly return $=$ $\$ 25,000 / y r)$. This number, combined with an explanation of the impact that the new funding would make, is a good way to justify the internal needs of the program. This method is controllable and fairly simple to achieve and should probably be a core data point for most valuation projects.

\section{Market Method}

Benchmark against other similar programs at peer universities to see what they received for naming gifts, and then adjust the size of naming gift to match the size and resources of an institution. For example, Texas A\&M and New Mexico State University (NMSU) are both land grant universities, and in fact affiliates of both are called "Aggies", signifying the schools' common background as a place where agricultural education was provided. But the two schools have different economics in terms of state funding and in terms of the number and wealth of alumni. Accordingly, a departmental program at Texas A\&M named for $\$ 12$ million would be adjusted so as to be less for NMSU. Given NMSU is about $1 / 5$ th the size of Texas $A \& M$, this method would suggest that the naming would be equivalent to $\$ 2-3$ million.

Although this method can work well for some types of programs, there are significant limitations to this method (e.g., identifying peer programs and gift amounts; adjusting for time, scale, and university/college differences.). Thus, in the case of New Mexico State
University this method would be more valuable if the University of New Mexico or University of Texas at El Paso, which are both similar in size and geography to NMSU, had a similar program or facility that was named recently. But the approach would be less useful when comparing to a Texas A\&M program, especially if that program was named at the peak of the oil boom.

\section{Build-up Method}

For new buildings with lots of naming opportunities, the "gift pyramid" can be used, which is driven by processes to allocate a total campaign goal among all of the various naming opportunities so that more visible/valuable real estate comes with a higher naming amount than smaller/less visible spaces.

This is a good method for allocating a total gift target between spaces but is reliant on setting an appropriate overall goal and ensuring that the donor base is capable of successfully supporting the overall campaign. Typically, this method involves "interviews" with many prospective donors to determine their level of interest and range of anticipated support to increase confidence in the campaign plan. This method typically also involves a quiet phase of the campaign when lead gifts in excess of $50 \%$ of the total are committed before going public with the campaign and making construction commitments.

\section{Income Method}

This is a "top down," donor-driven method based on how much a major donor is willing to give based on their income or net worth. When an entrepreneur has a huge windfall, say from going public or selling a business, the newsworthy nature of this alerts fundraisers, especially if the entrepreneur is an alum. A quick (Biblical) rule of thumb is the donor should be willing to donate $10 \%$ of this newfound wealth.

This donor-driven method is fine if a donor is identified and his or her interests align with college objectives. An advantage is this method allows the college to communicate to the donor what can be delivered with the gift funding available.

\section{Discounts and Premiums Applied to the Valuation}

Sometimes it can make sense to price a naming opportunity a little higher or lower than the standard methods would suggest. This is where discounts and 
premiums come in. A valuation discount refers to the deficiency in value that can be estimated for a naming while a valuation premium refers to the addition in value that can be estimated for a naming. When it comes to valuing a naming opportunity, it's important to be intimately knowledgeable with every aspect of discounts and premiums: the different types, the situations when they may or may not apply, and how to quantify them. Here are some variations on the discounting theme:

- Discount for the naming being in someone else's honor (50-75\% discount) -- One form of discounting a gift occurs when the program/project is being named in someone else's honor or the naming is split between two donors. For example, a group of alumni want to collectively name a gift in memory of a coach or professor. Although a naming in someone else's honor sounds good in principle, in practice honorary naming campaigns almost never succeed in raising substantial funds. For example, if the other methods above would point to a $\$ 2-3$ million valuation for a specific program, it seems that an honorary campaign might raise $\$ 500,000$, and that might be optimistic if no lead gift is identified.

- Discount for Lack of Marketability (35\% $50 \%$ discount) - A bad economy or lack of interest can also be a reason to discount the donation appropriate for a naming gift. This phenomenon comes to light after prolonged efforts by an institution to raise for a naming opportunity. For example, the economic conditions from 2008 to 2010 made it difficult to raise gifts of any type. Thus, the economic discount might be driven by fear that leads to holding onto assets. Lack of donors in general is a similar but different problem that may not improve even in times of positive economic conditions. In these situations, universities often conduct a feasibility study for larger campaigns to ensure that the donor base and interest exists to support the campaign assumptions and goals.

- Key Person Discount or Premium (50 - 75\% discount or premium) - When a key person associated with the program or in a leadership position within the college or university is viewed as a reputational asset, the prestige of the donor may create an incentive to discount the gift. A highly trusted and involved campus leader (e.g., a dean, department head, or president) can have an enormous impact on the success of a campaign. Conversely, disengaged or untrusted leadership can doom almost any campaign to failure.

\section{Which Valuation Method Should Be Used?}

When possible, all the valuation methods should be considered to establish the value of a naming opportunity. Once all the methods have been considered, the pros and cons of each method can be discussed for the specific naming opportunity and a decision can then be made regarding which valuation method is most applicable. In situations where there is no one best valuation method, different valuation methods can be used together as a basis for determining a range of value for the naming opportunity.

The key to a win-win outcome is for the institution to be transparent, and for the donor to be knowledgeable. Taken together, satisfied donors and satisfied institutions will result in healthier relationships and more sustained philanthropy over time. 